\title{
Reconstituted versus dry alfalfa hay in starter feed diets of Holstein dairy calves: Effects on growth performance, nutrient digestibility, and metabolic indications of rumen development
}

\author{
S. Kargar* and M. Kanani \\ Department of Animal Science, School of Agriculture, Shiraz University, Shiraz 71441-65186, Iran
}

\begin{abstract}
We investigated the effect of reconstitution of alfalfa hay on starter feed intake, nutrient digestibility, growth performance, rumen fermentation, selected blood metabolites, and health criteria of dairy calves during the pre- and postweaning periods. A total of 20 newborn male Holstein calves ( $3 \mathrm{~d}$ of age; $40.3 \pm 1.30 \mathrm{~kg}$ of body weight; $\pm \mathrm{SE}$ ) were assigned randomly to 1 of 2 treatments, a starter feed containing either $10 \%$ dry $(\mathrm{AH})$ or reconstituted alfalfa hay (RAH), each consisting of 10 calves. Alfalfa hay was reconstituted with water $24 \mathrm{~h}$ before feeding to achieve a theoretical dry matter content of $20 \%$. Both starter feeds had the same ingredients and nutrient compositions but differed in their dry matter content (91.2 and $83.8 \%$ dry matter for $\mathrm{AH}$ and $\mathrm{RAH}$, respectively). Calves were weaned on $\mathrm{d} 50$ and remained on the study until d 70. All calves had free access to fresh and clean drinking water and the starter feed at all times. During the study period, the average maximum temperature-humidity index was 73.8 units, indicating no degree of environmental heat load for dairy calves. Starter feed dry matter intake, total dry matter intake, and body weight (at weaning and at the end of the trial) were unaffected by treatment. Nutrient intake (except for total ether extract intake) increased during the postweaning period compared with the preweaning period. Average daily gain and feed efficiency were unchanged between treatments. Calves had higher average daily gain and skeletal growth during the postweaning period; however, feed efficiency was lower during the post- versus preweaning period. Calves fed RAH gained more hip width and body barrel compared with calves fed $\mathrm{AH}$ during the preweaning and all studied periods, respectively. Rectal temperature was similar between treatments, but feeding RAH decreased fecal score and
\end{abstract}

Received June 3, 2018.

Accepted January 9, 2019.

*Corresponding author: skargar@shirazu.ac.ir or skargar@wisc.edu general appearance score during the preweaning period. Apparent total-tract nutrient digestibility was not affected by reconstitution of alfalfa hay; however, reconstitution increased total-tract digestibility of neutral detergent fiber during the postweaning period. Ruminal fluid $\mathrm{pH}$, and concentrations and profile of total volatile fatty acids were unchanged between treatments. Molar concentration of propionate and acetate to propionate ratio increased and decreased, respectively, during the postweaning period. Reconstitution of alfalfa hay did not affect concentrations of glucose, $\beta$-hydroxybutyrate, blood urea $\mathrm{N}$, and albumin, and albumin to globulin ratio during the studied periods; however, reconstitution increased concentration of blood total protein during the overall period. Calves had higher concentrations of blood glucose and globulin during the preweaning and $\beta$-hydroxybutyrate during the postweaning period. Overall, reconstitution of alfalfa hay did not interact with calf phase (pre- vs. postweaning) to affect dry matter intake, growth performance, and metabolic indications of rumen development (measured as ruminal volatile fatty acids and selected blood metabolites), but improved health-related variables (fecal score and general appearance score) during the preweaning period.

Key words: dairy calf, hay, starter moisture, summer

\section{INTRODUCTION}

Decreasing raising costs per unit of gain in the preweaned calf without compromising the health of the animal is a critical aim for the producers that depends on starter feed DMI and associated development of the reticulo-rumen (Beiranvand et al., 2014; Mirzaei et al., 2015, 2017). Accordingly, starter feeds are formulated for calves to maximize DMI and ADG as well as VFA production (Beiranvand et al., 2014; Mirzaei et al., 2015; Pazoki et al., 2017). Metabolic stimulation of reticulo-rumen development is dependent on fermentation of consumed starter feed to VFA (especially butyrate and propionate), which plays a central role in ruminal epithelium differentiation and papillae devel- 
opment (Beiranvand et al., 2014; Mirzaei et al., 2015; Pazoki et al., 2017).

Starter feed diets for dairy calves are typically based on concentrate and a source of forage (hay or straw) and therefore are almost dry (Beiranvand et al., 2014, 2016; Pazoki et al., 2017; Omidi-Mirzaei et al., 2018). Earlier studies with heifers have revealed decreased (Khan et al., 2014) or no changes (Thomas et al., 1961) in DMI with increasing dietary moisture. More recently, Beiranvand et al. (2016) reported that adding water to concentrate part of starter diets (up to $50 \% \mathrm{DM}$ ) increased ADG and BW in dairy calves by increasing DMI and VFA (especially acetate and propionate) production. Part of the reason for this discrepancy may be explained by differences in moisture levels and methods used to manipulate moisture (e.g., adding water to concentrate or hay; Khan et al., 2014; Beiranvand et al., 2016).

Total mixed rations with higher moisture levels are in cake form (and very sticky; Beiranvand et al., 2016) and thought to be more susceptible to spoilage (especially at higher environmental temperatures; Felton and DeVries, 2010), and DMI will be decreased if feed is spoiled or not fresh, leading to increased feed waste and increased cost. Most forages offered to young calves are low in sugars and higher in more poorly fermented fiber (Beiranvand et al., 2014; Omidi-Mirzaei et al., 2018). Reconstituting hay by soaking in water can increase fiber digestibility by decreasing the ruminal digestion lag time (Pasha et al., 1994) or increase cation exchange capacity for some minerals (Van Soest, 1994), and therefore increase rumen buffering capacity and fecal consistency. The literature does not indicate effects of moisture content of starter feed diet by feeding reconstituted versus dry alfalfa hay on DMI and growth performance of milk-fed dairy calves. Therefore, the objective of this study was to determine the effects of feeding reconstituted versus dry alfalfa hay on DMI, weight gain, skeletal growth, apparent total-tract nutrient digestibility, rumen fermentation, selected blood metabolites, and health criteria of Holstein dairy calves. We hypothesized that reconstitution of alfalfa hay would increase growth performance of Holstein dairy calves, possibly through increased DMI.

\section{MATERIALS AND METHODS}

This study was performed from July 30 to October 21, 2017, at the Foudeh-Sepahan Agriculture and Animal Husbandry, Isfahan, Iran. All the animal procedures were approved by the Animal Care Committee of Shiraz University by the Iranian Council of Animal Care (1995). Air temperature and relative humidity in the pen areas were measured daily by Hobo Pro Series Temp probes (Onset Computer Corporation, Pocasset, MA). Temperature-humidity index (THI) was computed according the following formula: $\mathrm{THI}=0.8 \times$ maximum $\mathrm{T}+($ minimum $\mathrm{RH} / 100) \times($ maximum $\mathrm{T}-$ $14.4)+46.4$, in which $\mathrm{T}$ is the air temperature $\left({ }^{\circ} \mathrm{C}\right)$ and $\mathrm{RH}$ denotes the relative humidity (\%) (NRC, 2001).

\section{Calves, Treatments, and Management}

Twenty neonatal male Holstein calves (3 d of age; $40.3 \pm 1.30 \mathrm{~kg}$ of $\mathrm{BW}$; mean $\pm \mathrm{SE}$ ) were separated from their dams immediately after birth, weighed, and housed in a naturally ventilated barn with individual pens $(2.9 \mathrm{~m} \times 1.1 \mathrm{~m} \times 1.8 \mathrm{~m}$; length $\times$ width $\times$ height $)$. Fresh wood shavings was used as bedding and refreshed every day and manure was removed daily to keep the pens visibly clean and dry. Calves consumed a total of $5.5 \mathrm{~L}$ of colostrum with $3.5 \mathrm{~L}$ fed within $2 \mathrm{~h}$ of life and 2 $\mathrm{L}$ fed $8 \mathrm{~h}$ after the first feeding. On $\mathrm{d} 2$ of life, calves received transition milk (4 L) in 2 meals of equal volume (at 0900 and 1700 h). From d 3 onward, calves were fed individually with waste milk containing $2.93 \pm 0.23 \%$ fat and $2.78 \pm 0.20 \% \mathrm{CP}$ in steel buckets in 2 meals of equal volume per d (at 0900 and $1700 \mathrm{~h}$ ). Calves were offered milk at $6 \mathrm{~L} / \mathrm{d}$ from d 3 to $43,4 \mathrm{~L} / \mathrm{d}$ from d 44 to 46 , and $2 \mathrm{~L} / \mathrm{d}$ from d 47 to 49 of age. Calves were weaned on d 50 and remained on study until d 70 .

Calves were assigned randomly to 1 of 2 treatments, a starter feed concentrate containing either $10 \%$ dry (AH) or reconstituted alfalfa hay (RAH) as TMR throughout the study, each consisting of 10 calves. Both starter feeds had the same ingredients and nutrient compositions but differed in their DM content (91.2 and $83.8 \% \mathrm{DM}$ for $\mathrm{AH}$ and $\mathrm{RAH}$, respectively; Table 1). Third-cut alfalfa hay at $50 \%$ flowering was chopped (particle size distribution: $15.4 \pm 0.5 \%$ greater than 18 $\mathrm{mm}, 22.6 \pm 0.9 \%$ between 8 and $18 \mathrm{~mm}, 31.4 \pm 1.1 \%$ between 1.18 and $8 \mathrm{~mm}$, and $30.6 \pm 1.0 \%$ less than $1.18 \mathrm{~mm}$, and geometric mean particle $4.3 \pm 0.15 \mathrm{~mm}$ ) with a theoretical length of $30 \mathrm{~mm}$, using a harvesting machine with screen size regulator (Golchin Trasher Hay Co., Isfahan, Iran). Alfalfa hay was reconstituted (using tap water) $24 \mathrm{~h}$ before feeding by placing the required amount of dry hay into an industrial container (Iran Plast Co., Isfahan, Iran) to achieve a theoretical DM content of $20 \%$. Cereal grains (corn and barley), used in the starter feed, were ground using a hammer mill with $2 \mathrm{~mm}$ screen size (model 5543 GEN, Isfahan Dasht, Isfahan, Iran). Calves had free access to fresh and clean drinking water and TMR (fed in steel buckets) formulated according to the NRC (2001), allowing at least $10 \%$ refusals. 


\section{Feed Sampling and Analyses}

Throughout the study, refusals were removed daily immediately before provision of fresh TMR. Individual feed intake was determined daily at $0900 \mathrm{~h}$ by weighing the amounts of TMR offered and the amounts refused. To measure DM and chemical analyses, representative samples of alfalfa hay $(\mathrm{n}=7$; pooled within study period) and treatment TMR ( $\mathrm{n}=7$; pooled by diet within study period) were gathered immediately before the morning feeding every $10 \mathrm{~d}$ over the study period. The DM concentration of samples was measured by drying at $100^{\circ} \mathrm{C}$ in a forced-air oven for $24 \mathrm{~h}$ (AOAC International, 2002; method 925.40). After mixing, samples were ground to pass a 1-mm screen in a Wiley mill (Ogawa Seiki Co. Ltd., Tokyo, Japan) and analyzed in triplicate for CP using the Kjeldahl method (Kjeltec 1030 Auto Analyzer, Tecator, Höganäs, Sweden; AOAC International, 2002; method 955.04), ether extract (EE; AOAC International, 2002; method 920.39), ash (AOAC International, 2002; method 942.05), and NDF using a heat-stable $\alpha$-amylase $(100 \mu \mathrm{L} / 0.5 \mathrm{~g}$ of sample $)$ and sodium sulfite (Van Soest et al., 1991). The NFC component was computed as $100-(\mathrm{CP}+\mathrm{NDF}+\mathrm{EE}$ + ash) (NRC, 2001).

\section{Growth Index, Skeletal Measurements, and Health Criteria}

Body weight was recorded at birth and every $10 \mathrm{~d}$ thereafter before the morning feeding, and ADG ( $\mathrm{kg}$ of $\mathrm{BW} / \mathrm{d}$ ) was computed as the difference between BW taken every $10 \mathrm{~d}$ apart divided by 10 . Feed efficiency was calculated as $\mathrm{kg}$ of BW gain/total DMI (milk DM + starter feed DM). Body measurements including heart girth (circumference of the chest), withers height (distance from base of the front feet to the withers), body length (distance between the points of shoulder and rump), body barrel (circumference of the belly before feeding), hip height (distance from base of the rear feet to hook bones), and hip width (distance between the points of hook bones) of the calves were recorded at birth and every $10 \mathrm{~d}$ thereafter according to the method described by Pazoki et al. (2017). Health criteria of the calves were monitored daily during the preweaning period (d 1 to 49). Rectal temperature was recorded daily between 1300 to $1400 \mathrm{~h}$ using a thermometer (Qingdao Dacon Trading Co. Ltd., Shandong, China) placed in the rectum for $1 \mathrm{~min}$. Fecal score $(1=$ normal; $2=$ soft to loose; $3=$ loose to watery; $4=$ watery, mucous, and slightly bloody; and $5=$ watery, mucous, and bloody) and general appearance $(1=$ normal and alert; $2=$ ears drooped; $3=$ head and ears drooped, dull eyes, slightly lethargic; 4 = head and ears drooped, dull eyes, lethargic; and $5=$ severely lethargic) were recorded daily based on a 1 to 5 system while calves were in individual pens (Pazoki et al., 2017).

\section{Nutrient Digestibility}

During the postweaning period, 6 fecal grab samples per calf were taken via rectal palpation by hand to account for 4-h intervals $(0800,1200,1600,2000,2400$, $0400 \mathrm{~h}$ ) of the 24 -h day by rotating sampling times over the 2-d collection period. Fecal grab samples were gathered from the same 6 calves randomly selected per treatment on d $65(0800,1600$, and $2400 \mathrm{~h})$ to 66 $(1200,2000$, and $0400 \mathrm{~h})$, frozen daily, combined on an equal wet weight basis, and sub-sampled for analyses. A composite of 6 fecal samples over a 2-d period was used to diminish variation compared with using individual samples. Samples were dried at $60^{\circ} \mathrm{C}$ for $72 \mathrm{~h}$ and ground through a 1-mm screen in a Wiley mill (Ogawa Seiki Co. Ltd.). Apparent total-tract nutrient digestibility was estimated by quantifying acid insoluble ash as an internal marker in the feed (corrected for refusals) and fecal samples according to Van Keulen and Young (1977).

Table 1. Ingredients and chemical composition of the basal diet

\begin{tabular}{|c|c|}
\hline Item & Value \\
\hline \multicolumn{2}{|l|}{ Ingredient composition, $\%$ of DM } \\
\hline Alfalfa hay & 10.0 \\
\hline Corn grain, ground & 60.0 \\
\hline Barley grain, ground & 5.5 \\
\hline Soybean meal & 22.0 \\
\hline Vitamin and mineral mixture ${ }^{1}$ & 0.8 \\
\hline Calcium carbonate & 1.2 \\
\hline Salt & 0.5 \\
\hline \multicolumn{2}{|l|}{$\begin{array}{l}\text { Chemical composition, \% of DM } \\
\text { (unless otherwise noted) }\end{array}$} \\
\hline DM, $\%$ & 91.2 \\
\hline $\mathrm{CP}$ & 19.7 \\
\hline $\mathrm{NFC}^{2}$ & 55.3 \\
\hline NDF & 16.0 \\
\hline Ether extract & 3.5 \\
\hline Ash & 5.4 \\
\hline Calcium $^{3}$ & 0.72 \\
\hline Phosphorus $^{3}$ & 0.38 \\
\hline $\mathrm{ME},{ }^{3} \mathrm{Mcal} / \mathrm{kg}$ of DM & 3.10 \\
\hline $\mathrm{NE}_{\mathrm{M}},{ }^{3} \mathrm{Mcal} / \mathrm{kg}$ of DM & 2.32 \\
\hline $\mathrm{NE}_{\mathrm{G}},{ }^{3} \mathrm{Mcal} / \mathrm{kg}$ of $\mathrm{DM}$ & 1.77 \\
\hline
\end{tabular}

${ }^{1}$ Contained per kilogram of supplement: 975,000 IU of vitamin A, $750,000 \mathrm{IU}$ of vitamin D, 1,800 IU of vitamin E, $143 \mathrm{~g}$ of $\mathrm{Zn}, 76 \mathrm{~g}$ of $\mathrm{Mn}, 48.6 \mathrm{~g}$ of $\mathrm{Cu}, 19.5 \mathrm{~g}$ of Se, $18.4 \mathrm{~g}$ of Fe, $8 \mathrm{~g}$ of $\mathrm{Ca}$, and $1.3 \mathrm{~g}$ of Co. ${ }^{2} \mathrm{NFC}=100-(\mathrm{CP}+\mathrm{NDF}+$ ether extract + ash $)(\mathrm{NRC}, 2001)$.

${ }^{3}$ Calculated from NRC (2001). 


\section{Rumen Fluid Sampling and VFA Analyses}

Rumen fluid was gathered $4 \mathrm{~h}$ after the morning feeding at $d 35$ and 65 by a stomach tube fitted to a vacuum pump. To avoid saliva contamination, the first $50 \mathrm{~mL}$ of gathered rumen fluid was discarded. The $\mathrm{pH}$ of the original samples were recorded using a mobile $\mathrm{pH}$ meter (HI 8318, Hanna Instruments, Cluj-Napoca, Romania) calibrated before each reading. Rumen contents were squeezed through 4 layers of cheesecloth, and $8 \mathrm{~mL}$ of the rumen fluid was acidified with $2 \mathrm{~mL}$ of $25 \%$ metaphosphoric acid and stored at $-20^{\circ} \mathrm{C}$ until analyses for VFA by GC as described by Kargar et al. (2012).

\section{Blood Sampling and Analyses}

Blood samples $(7 \mathrm{~mL})$ were gathered from the jugular vein $4 \mathrm{~h}$ after the morning feeding into vacuum serum separator tubes containing clot activator on birth day and every $10 \mathrm{~d}$ thereafter over the study period and immediately placed on ice. Samples were centrifuged immediately at $3,000 \times g$ for $20 \mathrm{~min}$ at $4^{\circ} \mathrm{C}$, and $1.5 \mathrm{~mL}$ of serum was transferred into $2-\mathrm{mL}$ microtubes and kept immediately at $-20^{\circ} \mathrm{C}$ for next analyses. The concentrations of blood metabolites were spectrophotometrically (UNICCO, 2100, Zistchemi, Tehran, Iran) measured using commercially available kits [Pars Azmoon Co., Tehran, Iran; catalog numbers: glucose (1-500-017), BUN (1-400-029), total protein (1-500-028), and albumin (1-500-001)] according to the manufacturers' instructions. Globulin concentrations were calculated by subtracting albumin from total protein contents. The concentrations of BHB were determined using a commercial colorimetric kit (Randox Laboratories Ltd., Ardmore, UK) with a Technicon-RA 1000 Auto-analyzer (DRG Co., Marburg, Germany).

\section{Statistical Analyses}

Data were checked for normality before analyses using the UNIVARIATE procedure (SAS 9.4, SAS Institute Inc., Cary, NC). Data (blood variables) that were not normally distributed were transformed logarithmically. Data on nutrient intake, growth performance, rectal temperature, and blood variables were analyzed for preweaning (d 1 to 49 ) or postweaning periods (d 50 to 70) using the MIXED MODEL procedure of SAS as follows:

$$
\begin{aligned}
& Y_{i j k l m}=\mu+\text { Calf }_{i}+\text { Diet }_{j}+\text { Time }_{k}+\left(\text { Diet } \times \text { Time }_{j k}\right. \\
& +\beta\left(X_{i}-\bar{X}\right)+E_{i j k l}+e_{i j k l m},
\end{aligned}
$$

where $Y_{i j k l m}$ is the dependent variable; $\mu$ is the average experimental value; Calf $_{i}$ is the random effect of calf; Diet $_{j}$ is the fixed effect of experimental diets $j(j=\mathrm{AH}$ or RAH); Time $_{k}$ is the fixed effect of 1-d (rectal temperature) or 10-d (all other variables) period $k(k=$ number of 1- or 10-d period); (Diet $\times$ Time $)_{j k}$ represents the effect of the interaction between diet and time; $\beta\left(X_{i}-\bar{X}\right)$ designates the covariate variable, where the $\beta$ is the regression coefficient relating covariate factor to the variable measured, $X_{i}$ is the covariate factor for the $i$ th factor, and $\bar{X}$ is the overall mean of the covariate factor; $E_{i j k l}$ is the sampling error; and $e_{i j k l m}$ is the error term.

Those above-mentioned variables (except for rectal temperature) were analyzed for overall period (d 1 to 70) using the MIXED MODEL procedure of SAS as follows:

$$
\begin{aligned}
& Y_{i j k l m}=\mu+\text { Calf }_{i}+\text { Diet }_{j}+{\text { Calf } \text { phase }_{k}} \\
& +(\text { Diet } \times \text { Calf phase })_{j k}+\beta\left(X_{i}-\bar{X}\right)+E_{i j k l}+e_{i j k l m},
\end{aligned}
$$

where $Y_{i j k l m}$ is the dependent variable; $\mu$ is the average experimental value; $\mathrm{Calf}_{i}$ is the random effect of calf; Diet $_{j}$ is the fixed effect of experimental diets $j(j=\mathrm{AH}$ or RAH); Calf phase is the fixed effect of pre- or postweaning period $k$ ( $k=$ pre- or postweaning period); $(\text { Diet } \times \text { Calf phase })_{j k}$ represents the effect of the interaction between diet and calf phase (pre- vs. postweaning period); $\beta\left(X_{i}-\bar{X}\right)$ designates the covariate variable, where the $\beta$ is the regression coefficient relating covariate factor to the variable measured, $X_{i}$ is the covariate factor for the ith factor, and $\bar{X}$ is the overall mean of the covariate factor; $E_{i j k l}$ is the sampling error; and $e_{i j k l m}$ is the error term.

Data on fecal score and general appearance score were not normally distributed. Therefore, the GLIMMIX procedure of SAS was employed to fit the Poisson distribution using a log-link function. In GLIMMIX model similar to the first above-mentioned MIXED model, the effects of diet, time (1-d period), and diet by time interaction were considered as fixed and calf as a random effect. Various covariance structures [including CS, Simple, UN, TOEP, AR (1), ARH (1), and ANTE (1)] were tested to find the best-fitted structure for the model. Time (1- or 10-d period) and calf phase were modeled as a repeated measurement by using an autoregressive covariance structure (type 1) which was determined by the lowest Bayesian information criterion. Initial skeletal measurements and blood variables were considered as covariate for the skeletal growth and blood variables analyses, respectively. Least squares 
means for diet effects were separated using a Tukey adjustment when the overall $F$-test was $P \leq 0.05$.

Data on BW and nutrient digestibility were subjected to ANOVA according to the following model:

$$
Y_{i j}=\mu+\text { Diet }_{i}+e_{i j}
$$

where $Y_{i j}$ is the dependent variable; $\mu$ is the average experimental value, Diet $_{i}$ is the fixed effect of experimental diets $i(i=\mathrm{AH}$ or $\mathrm{RAH})$, and $e_{i j}$ is the error term.

\section{RESULTS}

\section{Environmental Condition, Nutrient Intake, Performance, and Health Criteria}

The average maximum temperature-humidity index, relative humidity, and maximum temperature were $73.8,9.2 \%$, and $32.3^{\circ} \mathrm{C}$, respectively, during the experimental period (Supplemental Figure S1; https://doi .org/10.3168/jds.2018-15153). The results on nutrient intake and growth measurements are shown in Tables
2 and 3, respectively. No interactions were observed between diet and time or diet and calf phase to affect nutrient intake, weight gain, feed efficiency, skeletal growth, and health-related variables. Irrespective of the dietary treatment, calves consumed higher nutrient intake during the postweaning period (calf phase effect: $P=0.001$ ); however, total EE intake, due to milk consumption, was higher during the pre- versus postweaning period ( 0.11 vs. $0.07 \mathrm{~kg} / \mathrm{d}$; calf phase effect: $P=0.001)$, respectively. Reconstitution of alfalfa hay did not affect nutrient intake during the studied periods. Initial BW (40.0 vs. $40.6 \mathrm{~kg}$ for $\mathrm{AH}$ vs. RAH), and $\mathrm{BW}$ at weaning (68.4 vs. $70.6 \mathrm{~kg}$ ) and at the end $(87.4$ vs. $92.8 \mathrm{~kg})$ of the trial were not different between treatments. Irrespective of the dietary treatment, ADG (calf phase effect: $P=0.001$ ) and skeletal growth (calf phase effect: $P=0.001$ ) increased during the postweaning period; however, feed efficiency was higher during the pre- versus postweaning period ( 0.55 vs. 0.49 ; calf phase effect: $P=0.03)$, respectively. Average daily gain, feed efficiency, and body growth measurements (including heart girth, withers height, body length, and hip height) were not affected by treatment; however,

Table 2. Nutrient intake as influenced by feeding dry $(\mathrm{AH})$ versus reconstituted alfalfa hay (RAH) to Holstein dairy calves

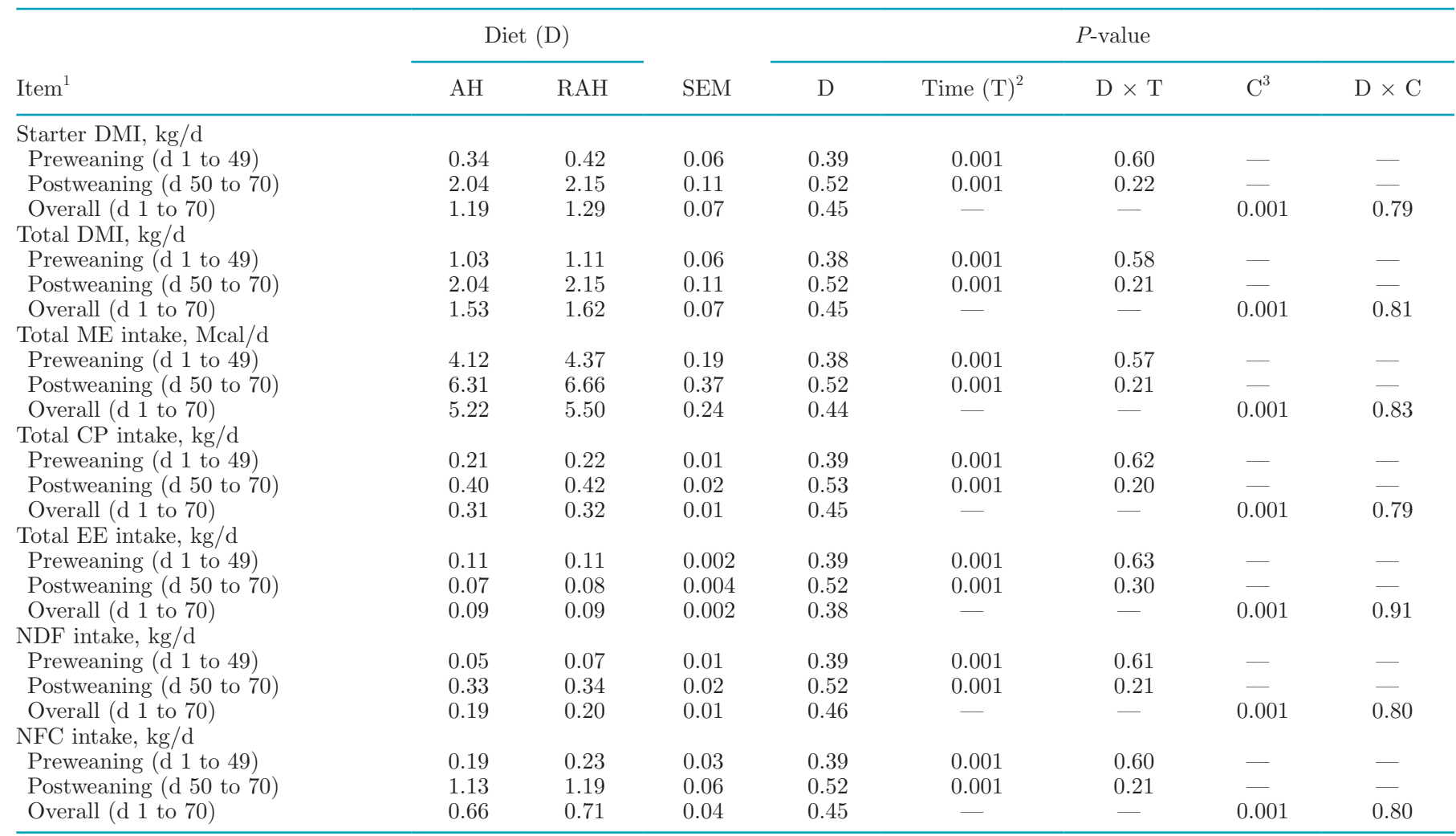

${ }^{1}$ Total DMI $=$ milk DM + starter feed DM; EE = ether extract.

${ }^{2}$ For all variables, time was used as $10-\mathrm{d}$ period.

${ }^{3} \mathrm{C}=$ calf phase (preweaning vs. postweaning). 
Table 3. Growth performance and health criteria (d 1 to 49) as influenced by feeding dry (AH) versus reconstituted alfalfa hay (RAH) to Holstein dairy calves

\begin{tabular}{|c|c|c|c|c|c|c|c|c|}
\hline Item & \multicolumn{2}{|c|}{ Diet (D) } & SEM & \multicolumn{5}{|c|}{$P$-value } \\
\hline Initial (d 1) & 40.0 & 40.6 & 1.30 & 0.74 & - & - & - & - \\
\hline Weaning (d 49) & 68.4 & 70.6 & 2.23 & 0.49 & - & - & - & - \\
\hline Final (d 70) & 87.4 & 92.8 & 3.25 & 0.26 & - & - & - & - \\
\hline Postweaning (d 50 to 70 ) & 0.95 & 1.11 & 0.06 & 0.09 & 0.01 & 0.80 & - & - \\
\hline Overall (d 1 to 70$)$ & 0.75 & 0.86 & 0.04 & 0.14 & - & - & 0.001 & 0.19 \\
\hline \multicolumn{9}{|l|}{ Feed efficiency ${ }^{3}$} \\
\hline Preweaning (d 1 to 49 ) & 0.54 & 0.55 & 0.02 & 0.81 & 0.001 & 0.73 & - & - \\
\hline Postweaning (d 50 to 70 ) & 0.46 & 0.52 & 0.02 & 0.06 & 0.45 & 0.73 & - & - \\
\hline Overall (d 1 to 70$)$ & 0.50 & 0.54 & 0.01 & 0.10 & - & - & 0.03 & 0.24 \\
\hline \multicolumn{9}{|l|}{ Skeletal growth, cm } \\
\hline \multicolumn{9}{|l|}{ Heart girth } \\
\hline Preweaning (d 1 to 49 ) & 82.3 & 83.1 & 0.59 & 0.36 & 0.001 & 0.45 & - & - \\
\hline Postweaning (d 50 to 70 ) & 89.2 & 90.3 & 0.90 & 0.40 & 0.001 & 0.23 & - & - \\
\hline Overall (d 1 to 70$)$ & 85.8 & 86.7 & 0.65 & 0.35 & - & - & 0.001 & 0.82 \\
\hline \multicolumn{9}{|l|}{ Body length } \\
\hline Preweaning (d 1 to 49) & 47.7 & 48.5 & 0.36 & 0.17 & 0.001 & 0.59 & - & - \\
\hline Postweaning (d 50 to 70$)$ & 54.5 & 56.3 & 0.79 & 0.15 & 0.001 & 0.83 & - & - \\
\hline Overall (d 1 to 70 ) & 51.2 & 52.5 & 0.53 & 0.11 & - & - & 0.001 & 0.23 \\
\hline \multicolumn{9}{|l|}{ Body barrel } \\
\hline Preweaning (d 1 to 49 ) & $93.9^{\mathrm{b}}$ & $96.7^{\mathrm{a}}$ & 0.89 & 0.05 & 0.001 & 0.43 & - & - \\
\hline Postweaning (d 50 to 70$)$ & $115.4^{\mathrm{b}}$ & $122.5^{\mathrm{a}}$ & 2.07 & 0.03 & 0.001 & 0.11 & - & - \\
\hline Overall (d 1 to 70$)$ & $104.9^{\mathrm{b}}$ & $109.4^{\mathrm{a}}$ & 1.37 & 0.04 & - & - & 0.001 & 0.13 \\
\hline \multicolumn{9}{|l|}{ Hip height } \\
\hline Preweaning (d 1 to 49 ) & 86.7 & 87.4 & 0.62 & 0.44 & 0.001 & 0.83 & - & - \\
\hline Preweaning (d 1 to 49 ) & $1.23^{\mathrm{a}}$ & $1.11^{\mathrm{b}}$ & 0.02 & 0.001 & 0.001 & 0.83 & - & - \\
\hline \multicolumn{9}{|l|}{ General appearance score ${ }^{5}$} \\
\hline Preweaning (d 1 to 49$)$ & $1.04^{\mathrm{a}}$ & $1.01^{\mathrm{b}}$ & 0.007 & 0.005 & 0.53 & 0.98 & - & - \\
\hline
\end{tabular}

${ }^{\mathrm{a}, \mathrm{b}}$ Means within a row with different superscripts are significantly different $(P \leq 0.05)$.

${ }^{1}$ For variables related on growth performance and health criteria, time was used as a 10- or 1-d period, respectively.

${ }^{2} \mathrm{C}=$ calf phase (preweaning vs. postweaning).

${ }^{3}$ Feed efficiency was calculated by dividing ADG by average total DMI (milk DM + starter feed DM).

${ }^{4}$ Where $1=$ normal; $2=$ soft to loose; $3=$ loose to watery; 4 = watery, mucous, and slightly bloody; and $5=$ watery, mucous, and bloody.

${ }^{5}$ Where 1 = normal and alert; 2 = ears drooped; 3 = head and ears drooped, dull eyes, slightly lethargic; $4=$ head and ears drooped, dull eyes, lethargic; and $5=$ severely lethargic.

RAH calves had a greater hip width $(P=0.03)$ and body barrel $(P \leq 0.05)$ during the preweaning and all studied periods, respectively. Rectal temperature was not affected by treatment during the preweaning period; however, feeding RAH decreased fecal score $(P$ $=0.001)$ and general appearance score $(P=0.005)$ compared with AH.

\section{Nutrient Digestibility and Rumen Fermentation Characteristics}

The results on apparent total-tract nutrient digestibility and rumen fermentation characteristics are shown in Table 4. During the postweaning period, apparent total-tract DM (79.2\%), OM (79.9\%), CP 
(73.6\%), NFC (88.6\%), and EE (85.2\%) digestibilities were not affected by treatment; however, digestibility of $\mathrm{NDF}$ (59.6 vs. $52.8 \% ; P=0.01$ ) increased in $\mathrm{RAH}$ versus $\mathrm{AH}$ calves, respectively. No interaction was observed between diet and calf phase to affect rumen fermentation characteristics. Ruminal fluid $\mathrm{pH}$, total and individual (acetate, propionate, butyrate, valerate, and iso-valerate) VFA production, and acetate to propionate ratio were not affected by treatment. Irrespective of the dietary treatment, molar concentration of propionate and acetate to propionate ratio increased (calf phase effect: $P=0.01$ ) and decreased (calf phase effect: $P=0.02$ ), respectively, during the postweaning period compared with preweaning period.

\section{Blood Metabolites}

The results on blood glucose, BHB, BUN, total protein, albumin, globulin, and albumin to globulin ratio are shown in Table 5. No interactions were observed between diet and time or diet and calf phase to affect concentrations of blood variables. Irrespective of the dietary treatment, concentrations of blood glucose ( 86.68 vs. $98.5 \mathrm{mg} / \mathrm{dL}$; calf phase effect: $P=0.001$ ) and globulin (4.13 vs. $3.54 \mathrm{~g} / \mathrm{dL}$; calf phase effect: $P$ $=0.05)$ were higher during the preweaning period but concentration of blood BHB was lower during the preversus postweaning period (0.05 vs. $0.19 \mathrm{mmol} / \mathrm{L}$, respectively; calf phase effect: $P=0.001)$. Concentrations of blood glucose, BHB, BUN, albumin, and globulin, and albumin to globulin ratio were not affected by treatment; however, concentration of blood total protein was higher in calves fed RAH than calves fed $\mathrm{AH}$ during the overall period.

\section{DISCUSSION}

Reconstitution of alfalfa hay decreased DM content of TMR (by $8.1 \%$ ) from $91.2 \%$ in $\mathrm{AH}$ to $83.8 \%$ in $\mathrm{RAH}$ but did not affect DMI during the studied periods. Thomas et al. (1961) reported that DMI in 8- to 20-moold dairy heifers was not affected by water addition to hay or changing the moisture content of haylage by drying. Khan et al. (2014) observed a reduction in DMI of dairy heifers (159 $\pm 11 \mathrm{~d}$ of age) when water was added to decrease DM content of TMR [60:40 forage (3:1 ratio of alfalfa hay to grass hay) to concentrate ratio] from 65 to $35 \%$, which was not in line with our findings. Adding water to concentrate portion of starter feed and decreasing DM content of dry TMR [10:90 forage (alfalfa hay) to concentrate ratio] from 90 to $50 \%$ increased DMI during the preweaning (by 51\%) and overall (by 27\%) periods (Beiranvand et al., 2016). Unlike our hypothesis, reconstitution of alfalfa hay was unable to encourage significant feed consumption in dairy calves. Direct amount of water intake by the calves plus digestive dynamics could have been changed by the moisture content of the diet and thereby affect feed consumption (Khan et al., 2014). Water intake was not recorded in the present study, but it is recom-

Table 4. Apparent total-tract nutrient digestibility and rumen fermentation characteristics as influenced by feeding dry (AH) versus reconstituted alfalfa hay (RAH) to Holstein dairy calves

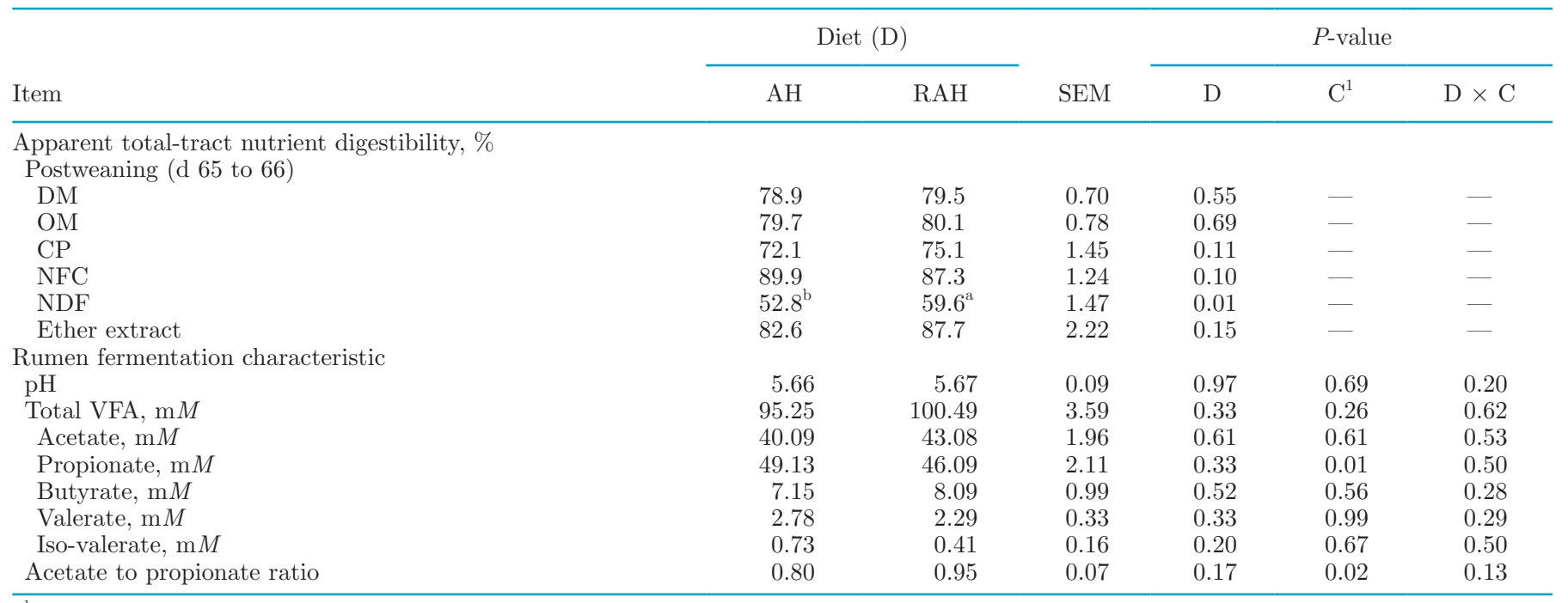

${ }^{\mathrm{a}, \mathrm{b}}$ Means within a row with different superscripts are significantly different $(P \leq 0.05)$.

${ }^{1} \mathrm{C}=$ calf phase (preweaning vs. postweaning). 
Table 5. Blood variables as influenced by feeding dry $(\mathrm{AH})$ versus reconstituted alfalfa hay (RAH) to Holstein dairy calves

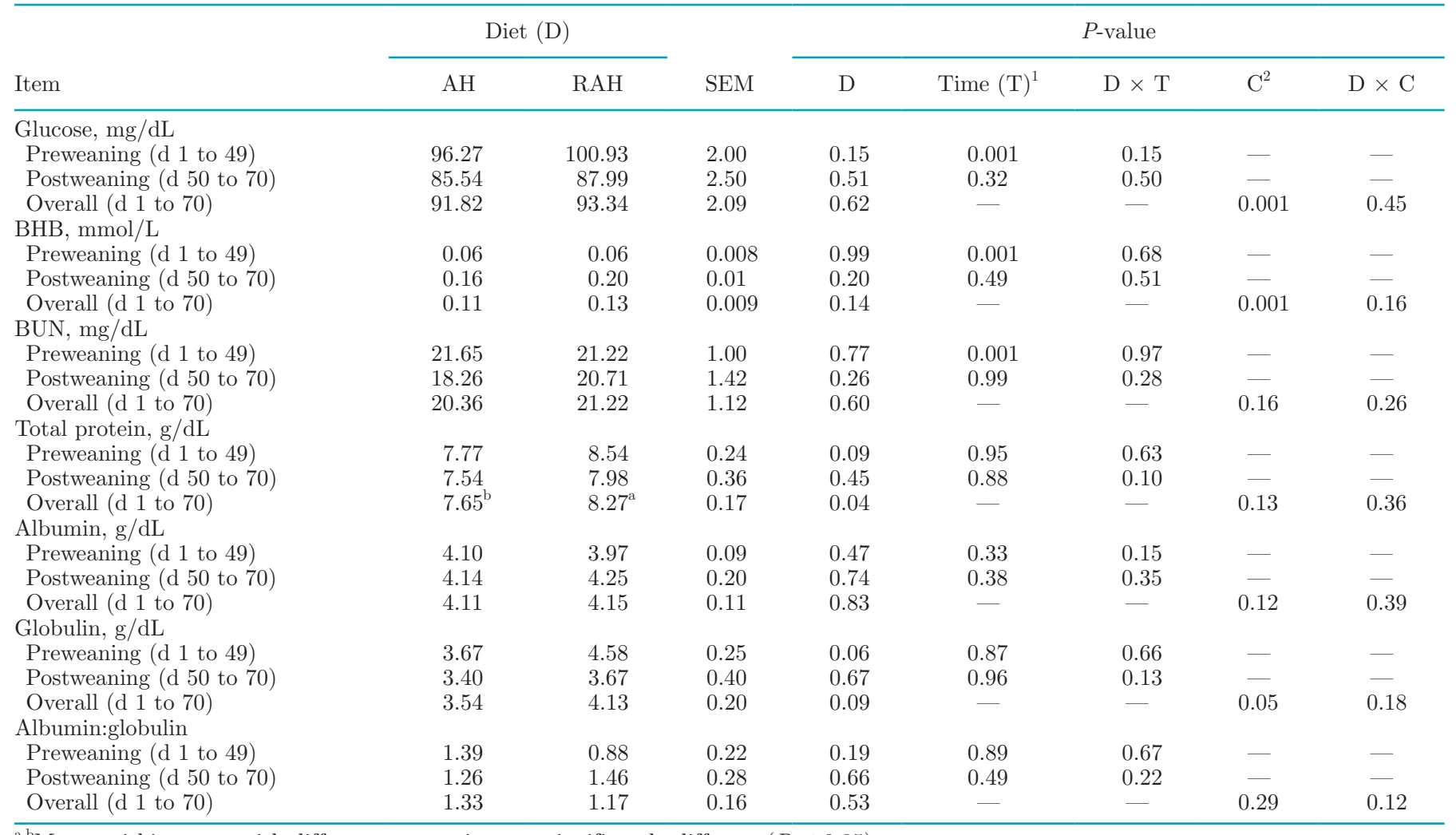

${ }^{\mathrm{a}, \mathrm{b}}$ Means within a row with different superscripts are significantly different $(P \leq 0.05)$.

${ }^{1}$ For all variables, time was used as a 10 -d period.

${ }^{2} \mathrm{C}=$ calf phase (preweaning vs. postweaning).

mended to be measured in future research. Despite this fact, addition of water directly into the rumen did not affect DMI in dairy heifers (Thomas et al., 1961).

Due to similar DMI and nutrient digestibility (except for NDF) in the present study, weight gain and BW were not affected by treatment. This is not in line with Beiranvand et al. (2016) who observed increased ADG and $\mathrm{BW}$ in calves fed moisturized starter feed. They attributed this effect to greater DMI but not feed digestibility as results of the improved TMR uniformity, adhesiveness, and lower dustiness (Beiranvand et al., 2016). However, hip width and body barrel gained more in calves fed RAH versus AH. In the present study, increased feed efficiency and ADG during the pre- and postweaning period, respectively, are consistent with the results reported by others (Beiranvand et al., 2014; Pazoki et al., 2017) who fed alfalfa hay to dairy calves.

To our knowledge, the effect of reconstitution of alfalfa hay on health criteria (e.g., rectal temperature, fecal score, and general appearance score) of dairy calves has not been investigated previously. Fresh-cut hay/pasture and salt (as a supplement) are recommended to feed dairy calves to avoid diarrhea during the preweaning period (Maas, 1999). Hydration increases availability and cation exchange capacity of forage for some macrominerals including Ca, Mg, and K (Van Soest, 1994). In immune cells, divalent cations (e.g., $\mathrm{Ca}$ and $\mathrm{Mg}$ ) have important roles as second messengers to regulate intracellular signaling pathways. Also, monovalent cations (e.g., $\mathrm{Na}$ and $\mathrm{K}$ ) mainly regulate the membrane potential, which indirectly controls the influx of $\mathrm{Ca}$ and immune cell signaling (Feske et al., 2015). Due to alfalfa containing greater concentrations of $\mathrm{K}$ and $\mathrm{Ca}$ than other macro-minerals (NRC, 2001), we speculate that reconstitution increased availability of $\mathrm{K}$ and $\mathrm{Ca}$ for RAH calves, improved their immune state (which is substantiated by an increase in blood total protein and globulin), and thereby decreased fecal score. Another explanation is that additional $\mathrm{K}$ and $\mathrm{Ca}$ available in the rumen can potentially lead to more buffering (Haaland and Tyrrell, 1982; Brink et al., 1984) and thereby improve the fecal consistency (Ferreira et al., 1980).

The effect of the reconstitution of alfalfa hay on nutrient digestibility is not completely understood. Increased NDF digestibility in RAH versus AH may be attributed to alfalfa hay hydration before ingestion (Pasha et al., 
1994) or higher $\mathrm{K}$ and $\mathrm{Ca}$ available in the rumen (Varner and Woods, 1972; Funk et al., 1986). Pasha et al. (1994) observed an increase in NDF digestibility when high-moisture forage was fed to sheep. They attributed this effect to decreased lag time of digestion in the rumen (Pasha et al., 1994). Higher fiber digestibility was reported when a source of K (Funk et al., 1986) or Ca (Varner and Woods, 1972) was supplemented to steers or lambs, respectively.

Consistent with the results reported by others (Lahr et al., 1983; Leonardi et al., 2005; Beiranvand et al., 2016), ruminal fluid $\mathrm{pH}$ was not affected by diet moisture. Lahr et al. (1983) and Leonardi et al. (2005) showed that decreasing DM content of TMR from 78 to $40 \%$ and from 80 to $64 \%$, respectively, by adding water did not affect total VFA concentrations and profile in dairy cows. Beiranvand et al. (2016) reported that due to greater DMI, concentrations of total ruminal VFA and the molar proportions of acetate and propionate increased linearly with decreasing dietary DM from 90 to $50 \%$. Similar ruminal fluid $\mathrm{pH}$ and total VFA concentrations and profile, in the present study, may be attributed to no changes in DMI and nutrient digestibility; however, an increase in NDF digestibility was unable to affect those mentioned variables. Due to higher DMI, molar proportion of propionate increased and acetate to propionate ratio decreased during the post- versus preweaning period, respectively.

Due to similar DMI and nutrient digestibility (except for NDF), the findings of the present study indicated that reconstitution of alfalfa hay had no significant effects on metabolic indications of rumen development (including concentrations of blood glucose, BHB, and BUN) of young calves during the overall period. As expected, we observed a gradual increase in blood BHB concentration as calves aged, indicating a normal physiological fuel shift in the source of energy from glucose to short-chain fatty acids with the initiation of ruminal fermentation and development (Beiranvand et al., 2016). This was substantiated by lower blood glucose and higher blood BHB concentrations during the post- versus preweaning period.

\section{CONCLUSIONS}

Reconstitution of alfalfa hay did not interact with calf phase to affect feed intake, growth performance, or metabolic indications of rumen development (measured as ruminal VFA and selected blood metabolites), but improved health-related variables (fecal score and general appearance score) during the preweaning period.

\section{ACKNOWLEDGMENTS}

The authors thank Shiraz University (Shiraz, Iran) for providing suitable experimental conditions. The authors express their kind appreciation to the farm staff at Foudeh-Sepahan Agriculture and Animal Husbandry (Isfahan, Iran), for diligent animal care, and to Mohammad Golkar and Morteza Nemati (Isfahan University of Technology, Isfahan, Iran), Mehdi Mirzaei (Arak University, Arak, Iran), Yadollah Moharrami, Naser Dadkhah, and Ali Agha-Tehrani (Foudeh-Sepahan Agriculture and Animal Husbandry, Isfahan, Iran), Abolfazl Soltani (University of Tehran, Karaj, Iran), and Ehsan Mahjoubi (University of Zanjan, Zanjan, Iran) for their help in conducting this experiment.

\section{REFERENCES}

AOAC International. 2002. Official Methods of Analysis. 17th ed. AOAC International, Arlington, VA.

Beiranvand, H., G. R. Ghorbani, M. Khorvash, A. Nabipour, M. Dehghan-Banadaky, A. Homayouni, and S. Kargar. 2014. Interactions of alfalfa hay and sodium propionate on dairy calf performance and rumen development. J. Dairy Sci. 97:2270-2280.

Beiranvand, H., M. Khani, S. Omidian, M. Ariana, R. Rezvani, and M. H. Ghaffari. 2016. Does adding water to dry calf starter improve performance during summer? J. Dairy Sci. 99:1903-1911.

Brink, D. R., O. A. Turgeon Jr., D. L. Harmon, R. T. Steele, T. L. Mader, and R. A. Britton. 1984. Effects of additional limestone of various types on feedlot performance of beef cattle fed high corn diets differing in processing method and potassium level. J. Anim. Sci. 59:791-797.

Felton, C. A., and T. J. DeVries. 2010. Effect of water addition to a total mixed ration on feed temperature, feed intake, sorting behavior, and milk production of dairy cows. J. Dairy Sci. 93:2651-2660.

Ferreira, J. J., C. H. Noller, R. B. Keyser, and T. S. Stewart. 1980 Influence of dietary calcium and protein on fecal pH, consistency, and rate of passage in dairy cattle. J. Dairy Sci. 63:1091-1097.

Feske, S., H. Wulff, and E. Y. Skolnik. 2015. Ion channels in innate and adaptive immunity. Annu. Rev. Immunol. 33:291-353.

Funk, M. A., M. L. Galyean, and T. T. Ross. 1986. Potassium and lasalocid effects on performance and digestion in lambs. J. Anim. Sci. 63:685-691.

Haaland, G. L., and H. F. Tyrrell. 1982. Effects of limestone and sodium bicarbonate buffers on rumen measurements and rate of passage in cattle. J. Anim. Sci. 55:935-942.

Iranian Council of Animal Care. 1995. Guide to the Care and Use of Experimental Animals, Vol. 1. Isfahan University of Technology, Isfahan, Iran.

Kargar, S., G. R. Ghorbani, M. Alikhani, M. Khorvash, L. Rashidi, and D. J. Schingoethe. 2012. Lactational performance and milk fatty acid profile of Holstein cows in response to dietary fat supplements and forage:concentrate ratio. Livest. Sci. 150:274-283.

Khan, M. A., A. Bach, L. Castells, D. M. Weary, and M. A. G. vonKeyserlingk. 2014. Effects of particle size and moisture levels in mixed rations on the feeding behavior of dairy heifers. Animal 8:1722-1727.

Lahr, D. A., D. E. Otterby, D. G. Johnson, J. G. Linn, and R. G. Lundquist. 1983. Effects of moisture content of complete diets on feed intake and milk production of cows. J. Dairy Sci. 66:1891-1900.

Leonardi, C., K. J. Shinners, and L. E. Armentano. 2005. Effect of different dietary geometric mean particle length and particle size distribution of oat silage on feeding behavior and productive performance of dairy cattle. J. Dairy Sci. 88:698-710. 
Maas, J. 1999. Preventing calf diarrhea. California Cattleman. Accessed Feb. 15, 2019. http://ucanr.edu/sites/UCCE_LR/files/ 151979.pdf.

Mirzaei, M., M. Khorvash, G. R. Ghorbani, M. Kazemi-Bonchenari, and M. H. Ghaffari. 2017. Growth performance, feeding behavior, and selected blood metabolites of Holstein dairy calves fed restricted amounts of milk: No interactions between sources of finely ground grain and forage provision. J. Dairy Sci. 100:1086-1094.

Mirzaei, M., M. Khorvash, G. R. Ghorbani, M. Kazemi-Bonchenari, A. Riasi, A. Nabipour, and J. J. G. C. van den Borne. 2015. Effects of supplementation level and particle size of alfalfa hay on growth characteristics and rumen development in dairy calves. J. Anim. Physiol. Anim. Nutr. (Berl.) 99:553-564.

NRC. 2001. Nutrient Requirement of Dairy Cattle. 7th rev. ed. Natl. Acad. Sci., Washington, DC.

Omidi-Mirzaei, H., A. Azarfar, A. Kiani, M. Mirzaei, and M. H. Ghaffari. 2018. Interaction between the physical forms of starter and forage source on growth performance and blood metabolites of Holstein dairy calves. J. Dairy Sci. 101:6074-6084.

Pasha, T. N., E. C. Prigge, R. W. Russell, and W. B. Bryan. 1994. Influence of moisture content of forage diets on intake and digestion by sheep. J. Anim. Sci. 72:2455-2463.
Pazoki, A., G. R. Ghorbani, S. Kargar, A. Sadeghi-Sefidmazgi, J. K. Drackley, and M. H. Ghaffari. 2017. Growth performance, nutrient digestibility, ruminal fermentation, and rumen development of calves during transition from liquid to solid feed: Effects of physical form of starter feed and forage provision. Anim. Feed Sci. Technol. 234:173-185.

Thomas, J. W., L. A. Moore, M. Okamoto, and J. F. Sykes. 1961. A study of factors affecting rate of intake of heifers fed silage. J. Dairy Sci. 44:1471-1483.

Van Keulen, J., and B. A. Young. 1977. Evaluation of acid-insoluble ash as a natural marker in ruminant digestibility studies. J. Anim. Sci. 44:282-287.

Van Soest, P. J. 1994. Nutritional Ecology of the Ruminant. 2nd ed. Cornell University Press, Ithaca, NY.

Van Soest, P. J., J. B. Robertson, and B. A. Lewis. 1991. Methods for dietary fiber, neutral detergent fiber, and nonstarch polysaccharides in relation to animal nutrition. J. Dairy Sci. 74:3583-3597.

Varner, L. W., and W. Woods. 1972. Effect of calcium and starch additions upon ration digestibility by steers. J. Anim. Sci. 35:410-414. 